\title{
The impact of life skills education on adolescent sexual risk behaviors [Arabic]
}

Robert Magnani

Kate Macintyre

Ali Mehyrar Karim

Lisanne Brown

Paul Hutchinson

Follow this and additional works at: https://knowledgecommons.popcouncil.org/departments_sbsr-hiv How does access to this work benefit you? Let us know!

\section{Recommended Citation}

Magnani, Robert, Kate Macintyre, Ali Mehyrar Karim, Lisanne Brown, and Paul Hutchinson. 2003. "The impact of life skills education on adolescent sexual risk behaviors [Arabic]," Horizons Research Summary. Washington, DC: Population Council. 
فلف ف الصحة الانجلبية

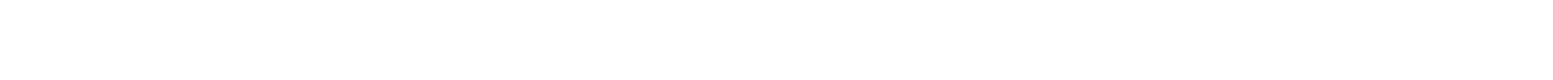

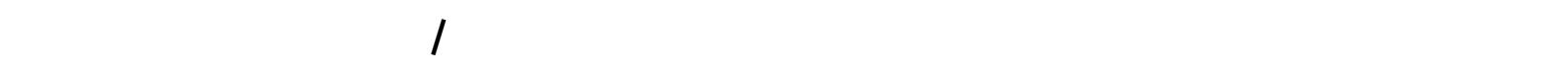

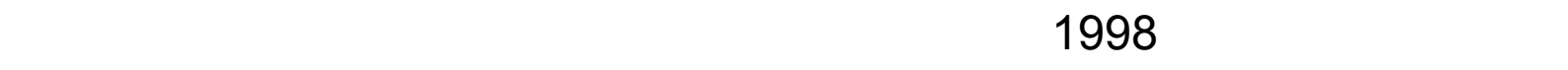

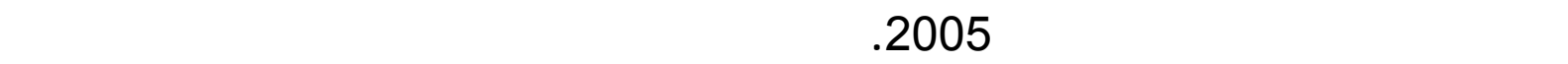

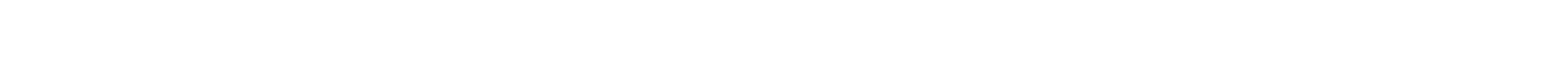

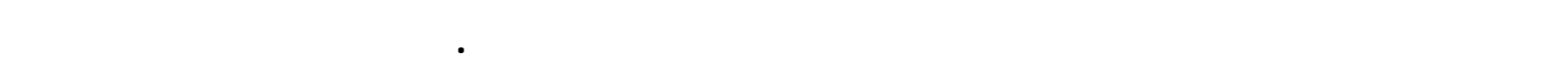

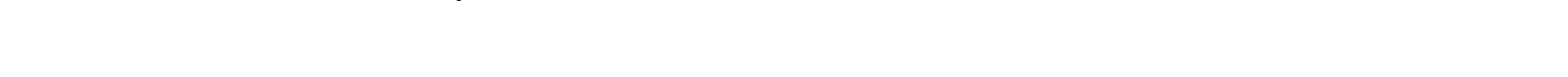

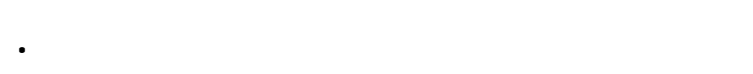

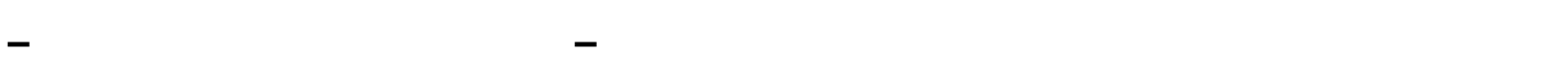

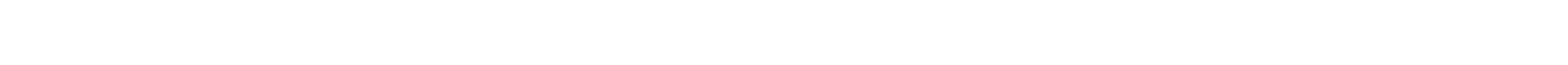
كوازولونالتل خلال الفترةمن علم 1999 إلل علم 2001. ألهدف برنامج المهارت الحيانية

نتيجة الترض اللالاب لبرنامج التربية علل المهارك الحيلتية، من المتوقع أن يصبحوا قالرين علل ما يلي:

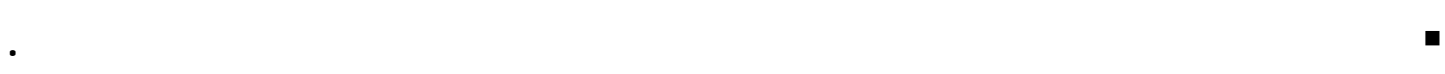

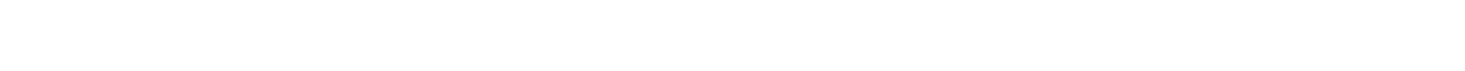

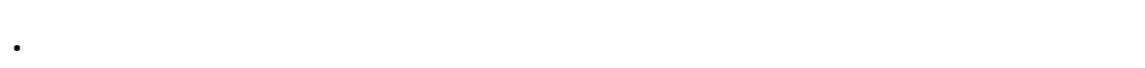

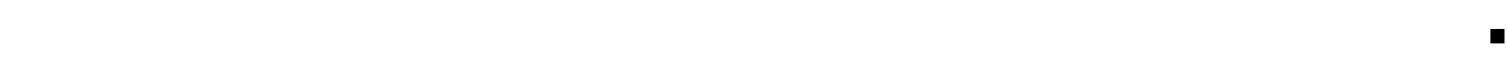
الأخرى المقولة جنيم فئسا.

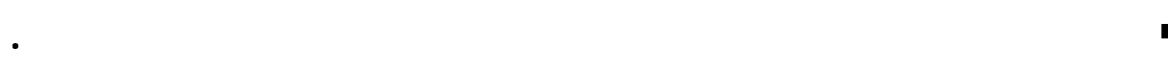

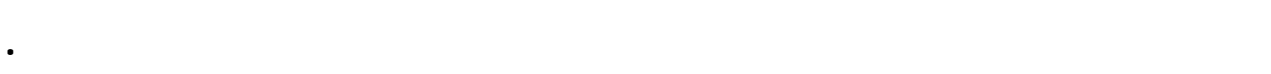

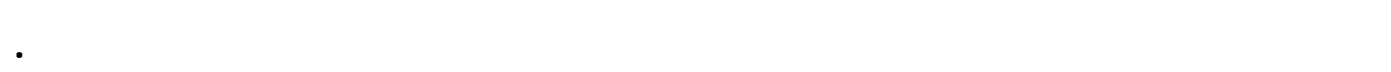

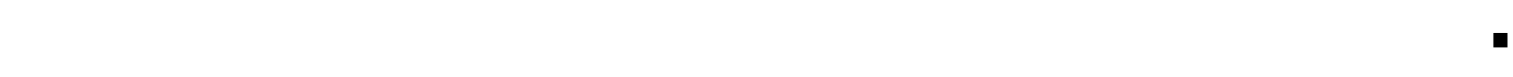

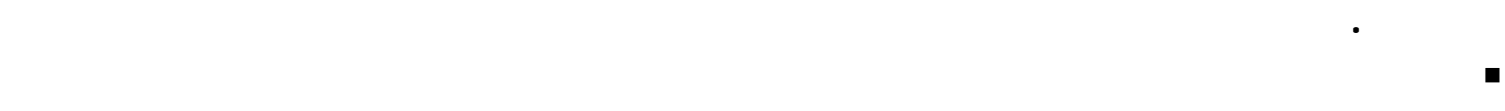
الحيلة جلرقة إيجلبية.

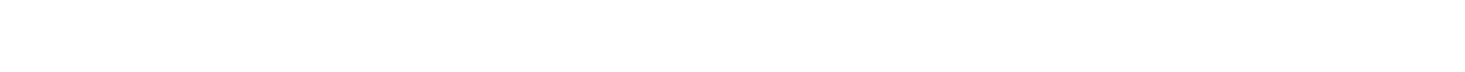

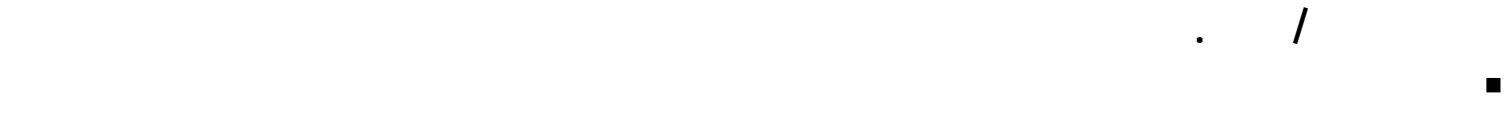
المكنسب/الإينز.

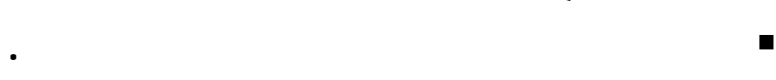
موقع الررلسة وتصميم العينة 


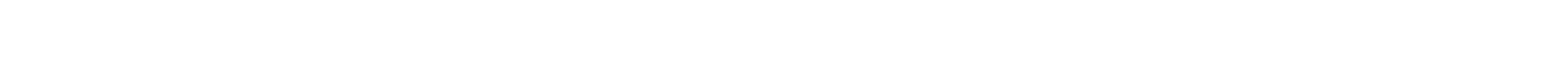

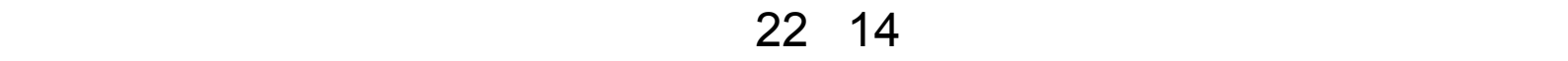

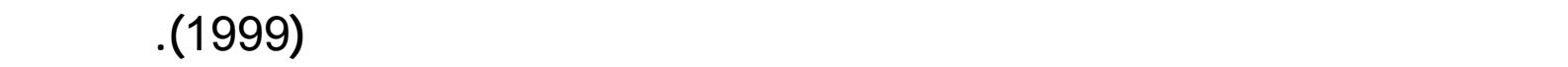

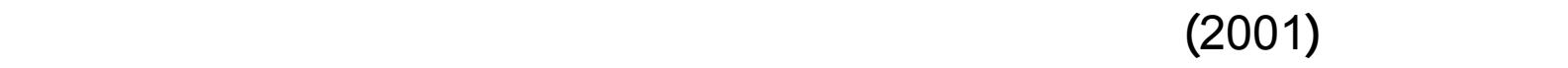

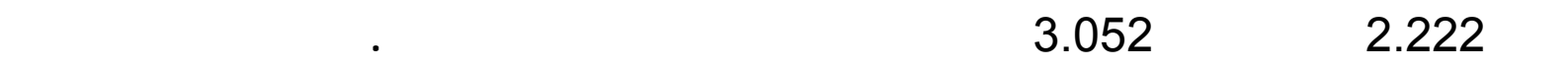

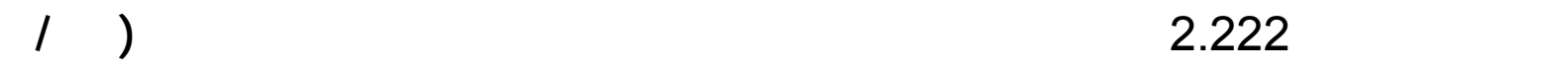

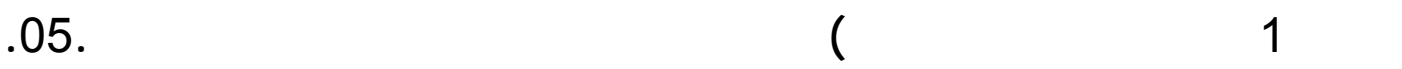

جرط 1: نسبة توزيع المبحوثن عل أسطب الخصائص الخهية (عدد = 2.222)

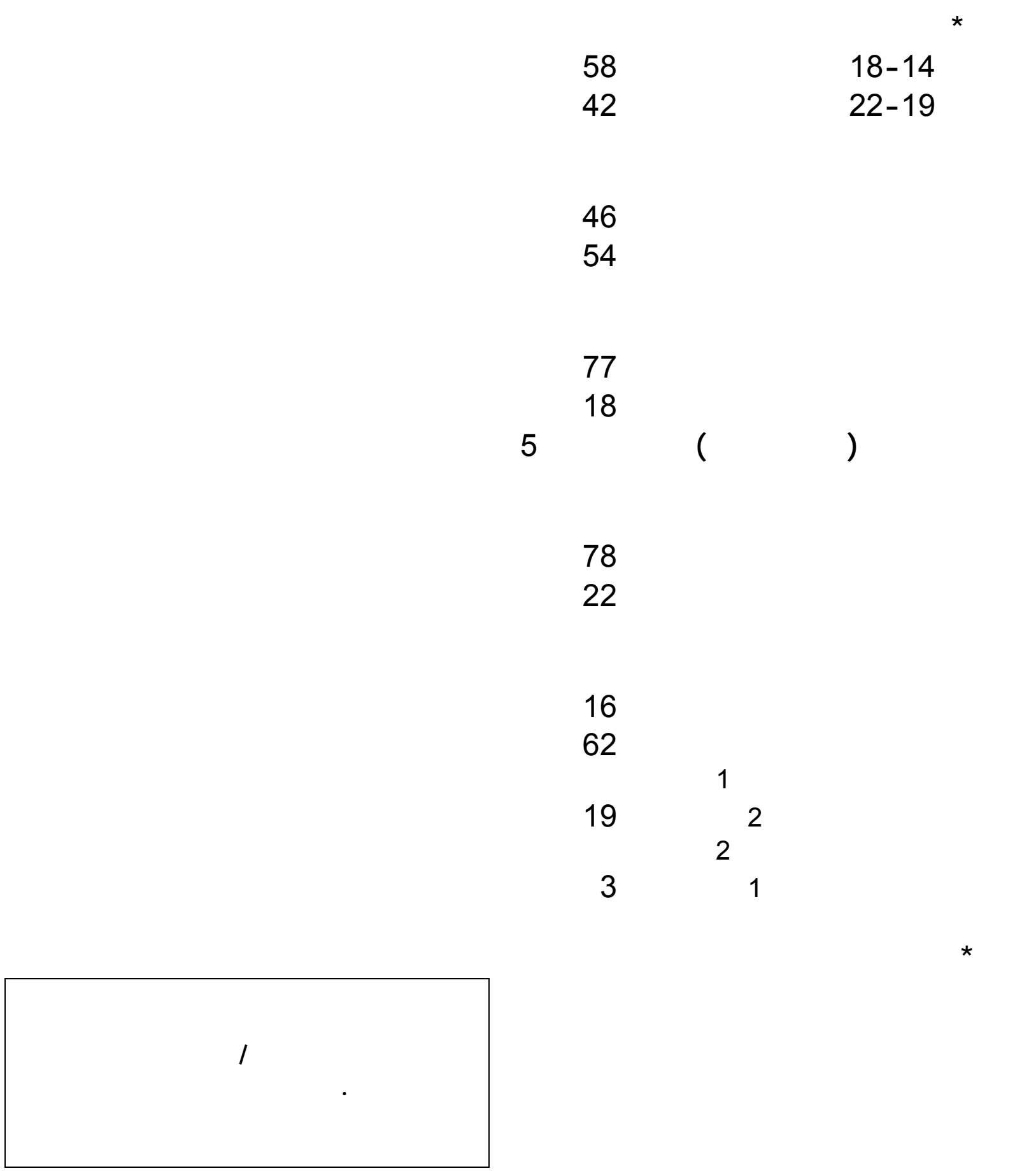




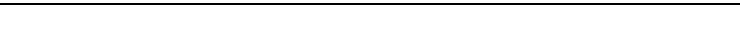

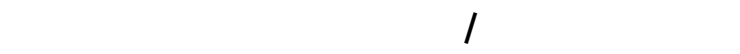

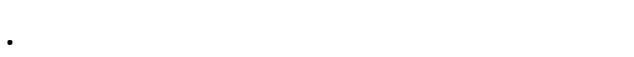

الوسلل

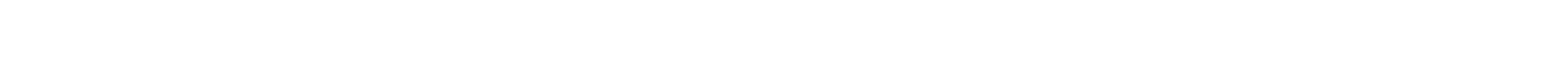

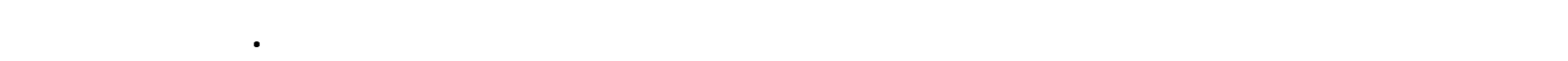

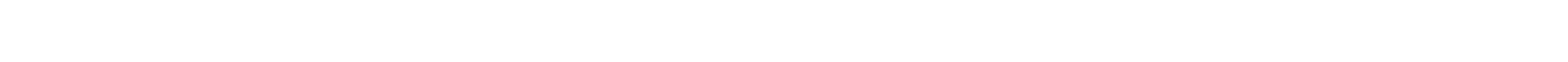

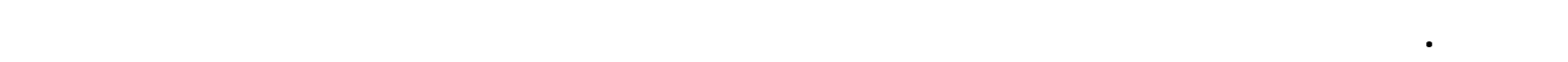

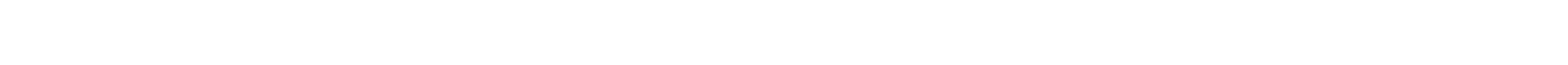

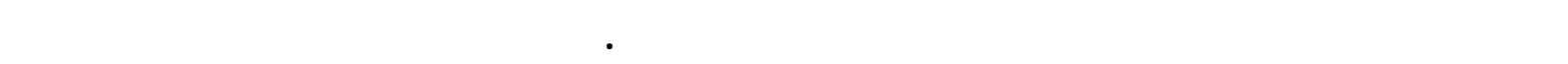

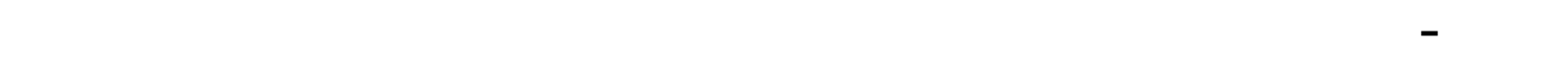

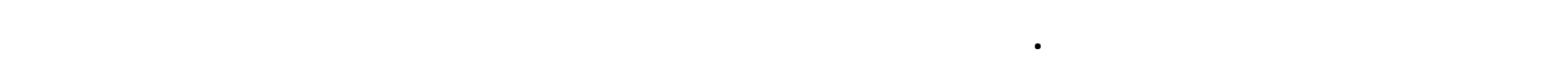

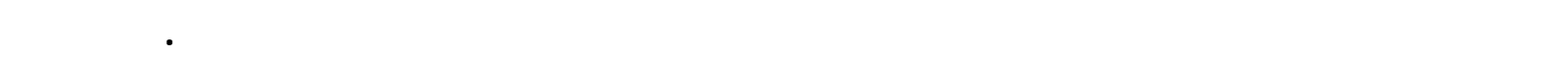

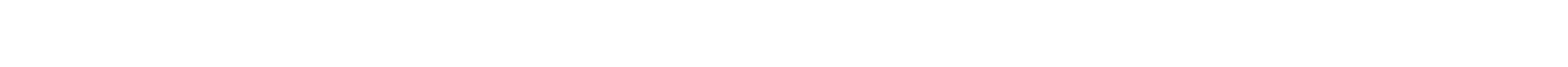

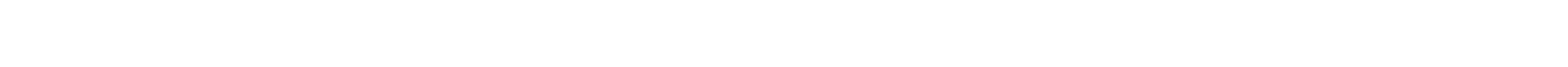
والاتجلهلت العاملنية العالمة.

قم قيلس التعرض لالمهارل الحيلنية عل ألسطس تصريح المستجوين بأنهم قد تهالموا حولالي 11

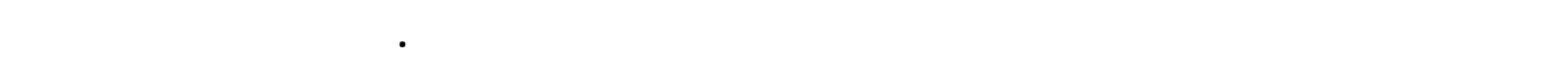

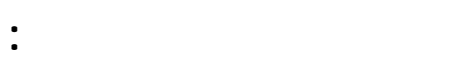

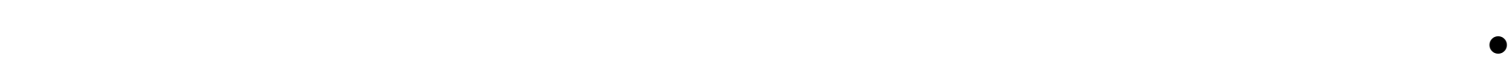

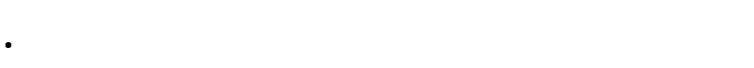

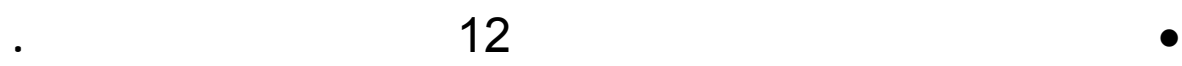

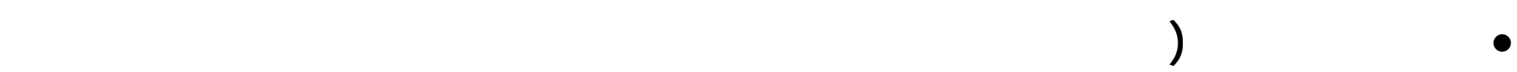
ممارسة جنسية، والانساق في الستهمل الولفي مع جميع اللثركاء).

\section{الاستنالجلت الأسلسية}

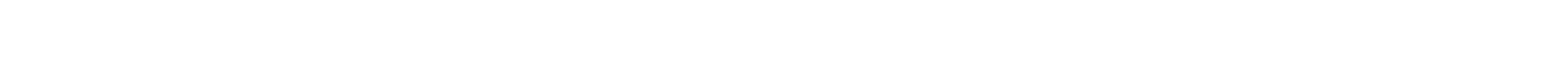

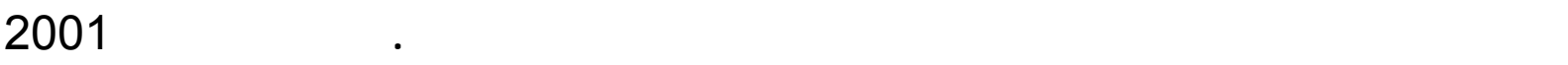

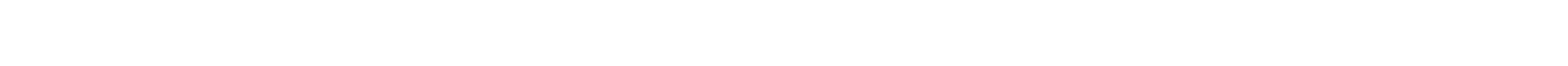

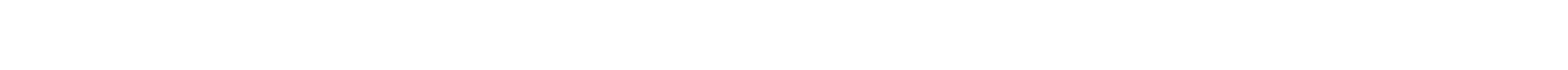

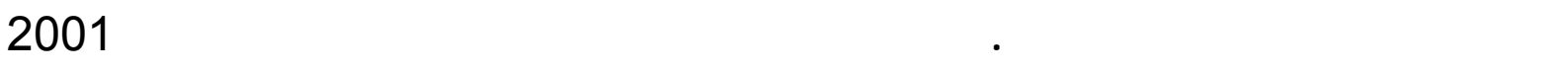

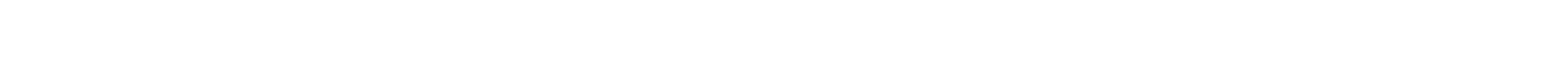
. 1999 de

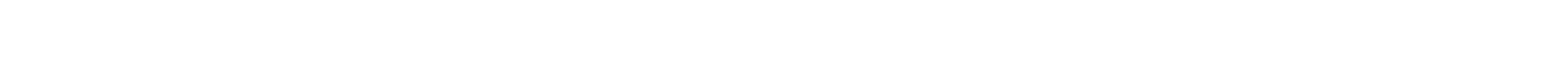

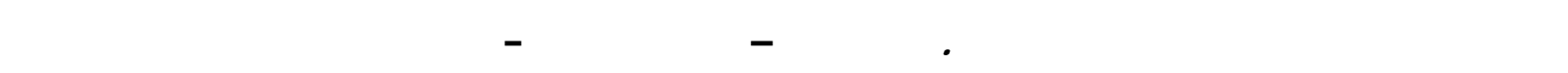

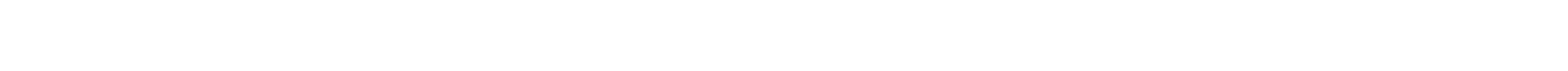

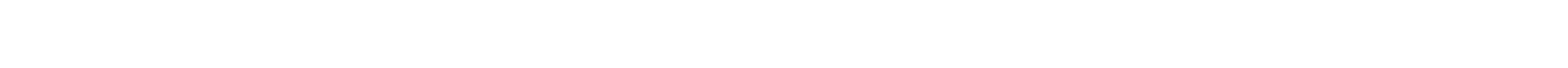




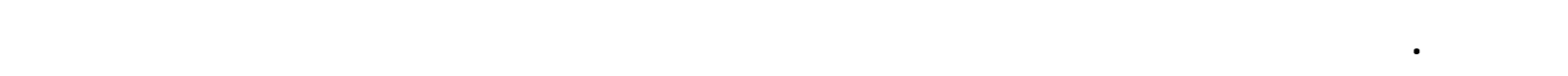

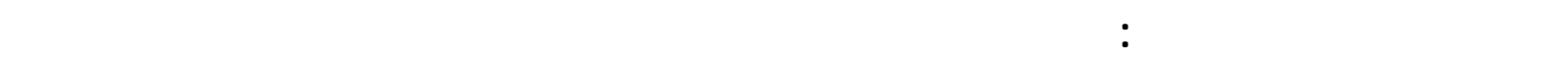

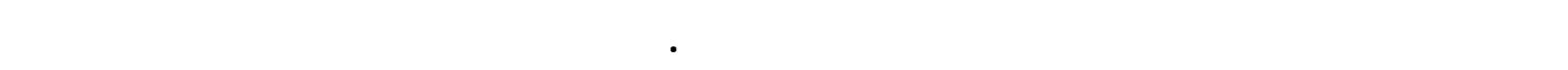

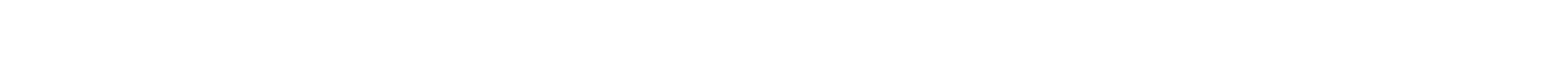

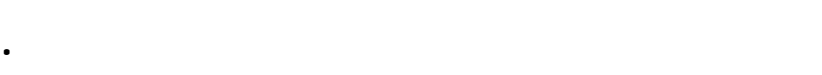

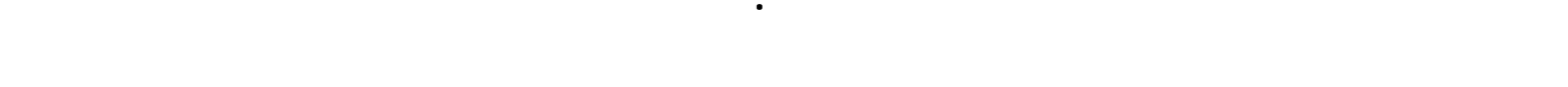

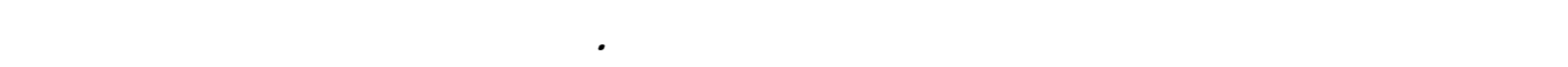

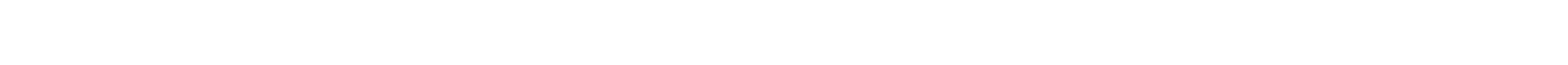

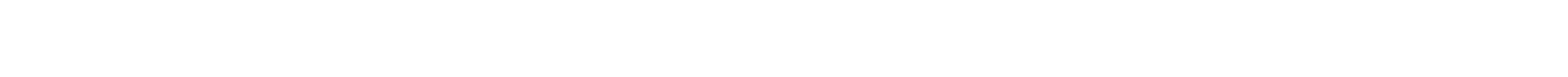

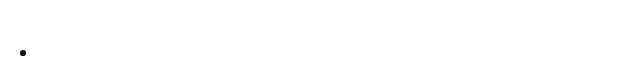

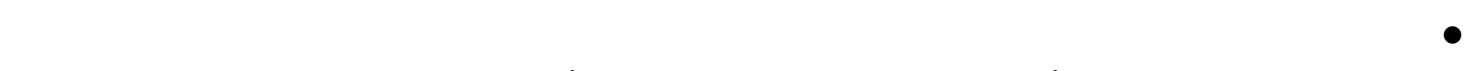

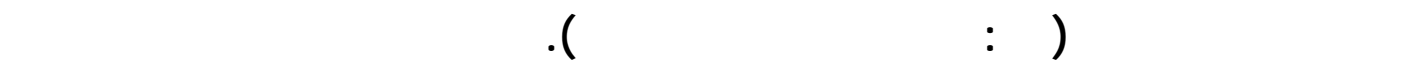

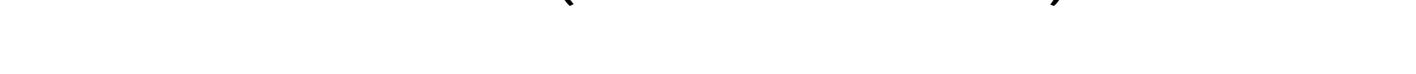

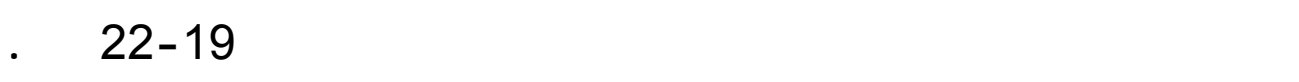

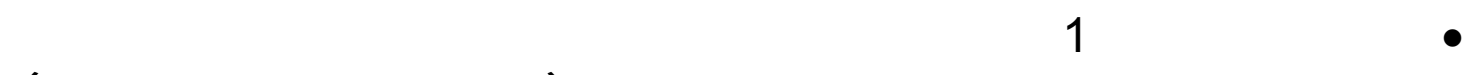

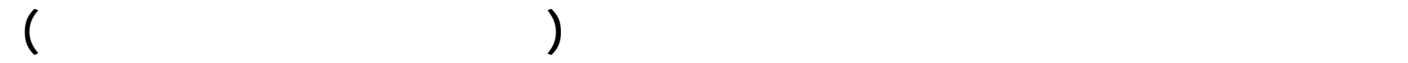

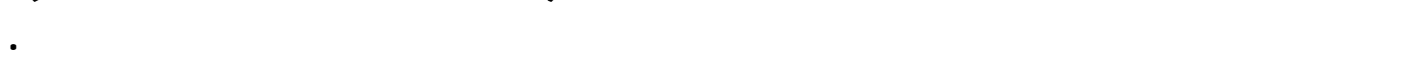

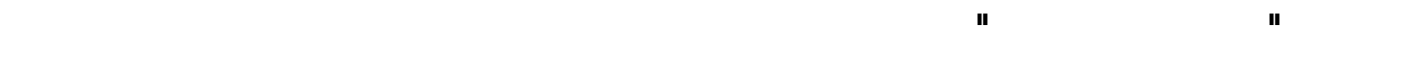

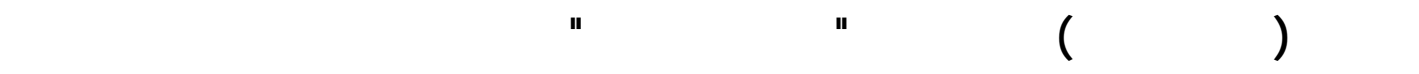

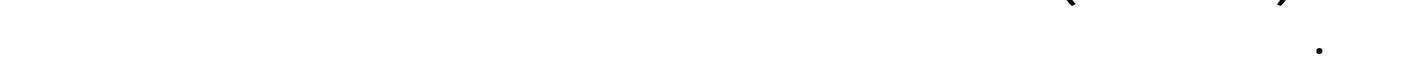

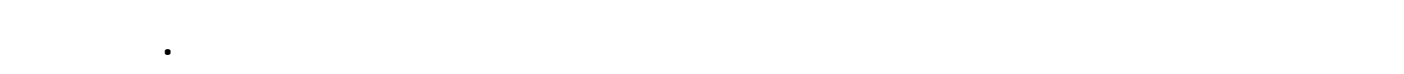

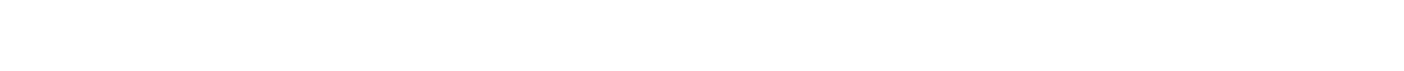
عند المماوسة الجنسية الأولى.

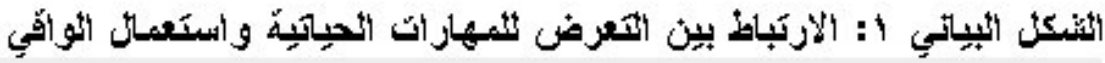

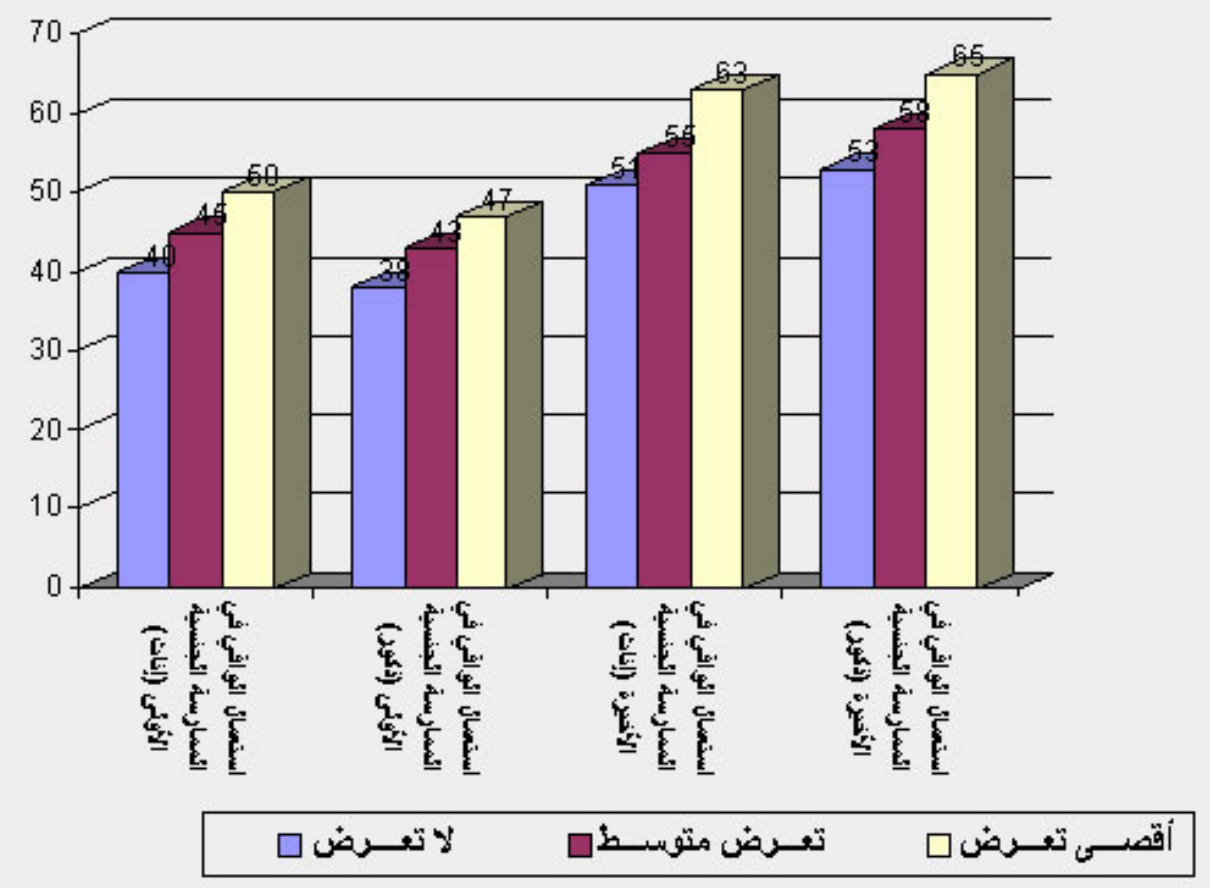




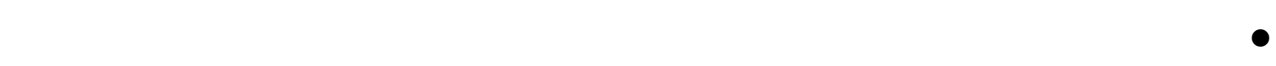

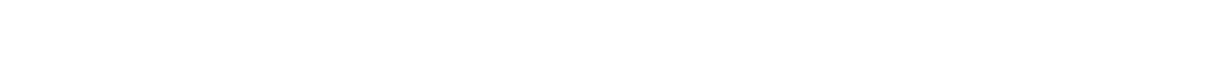

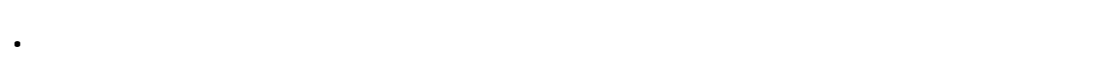

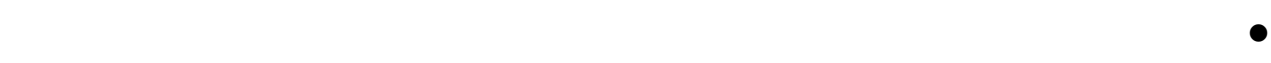

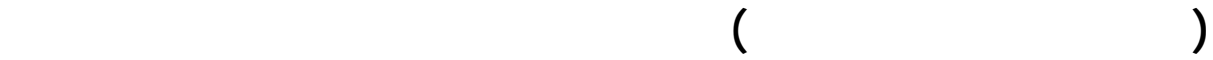

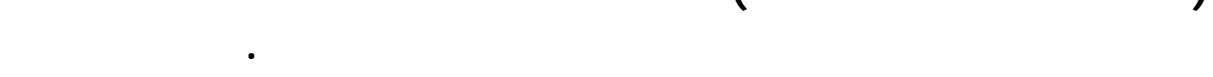

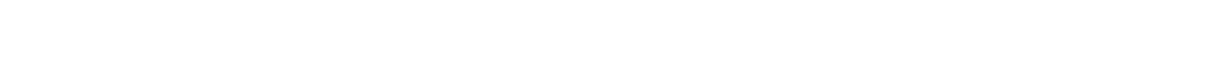

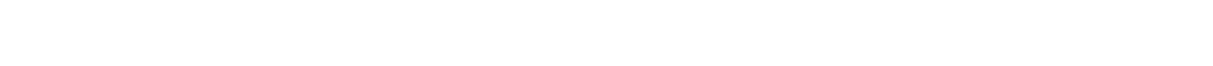
الحيلنية. • كما أثر النعرض لإمهارات الحيلتية عل عدد الشركاء النين يم الإشارة

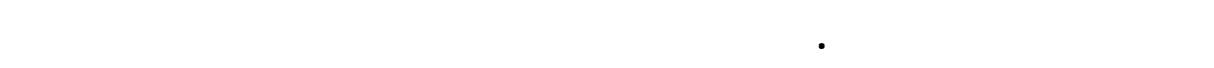

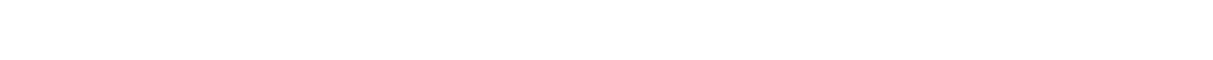

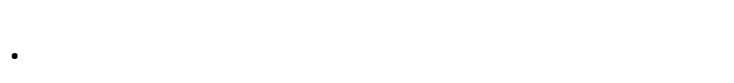

\section{اللستخلصل وما يترتب علبهاف تصميم البرالمج}

تشير لاستنتاجلت إلل آثار مهومة عل الأمد الفصير والمتويط نالتجة عن النعرض لالمهارل

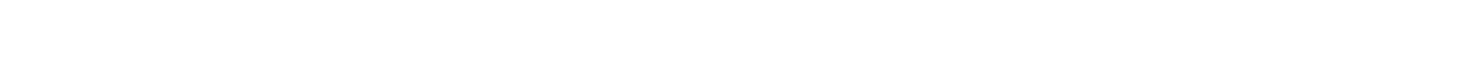

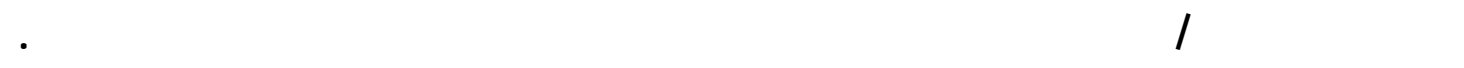

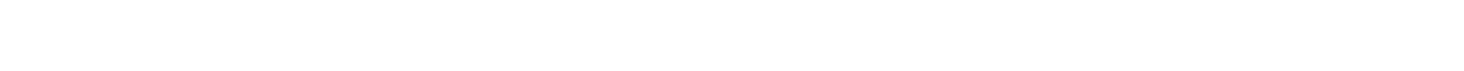

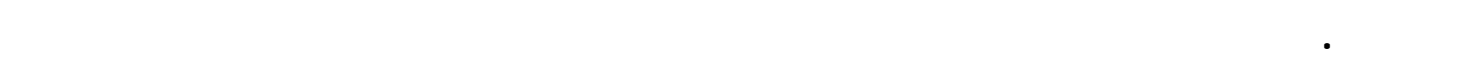

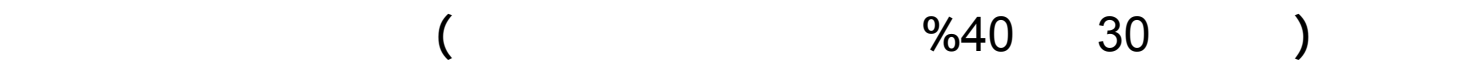

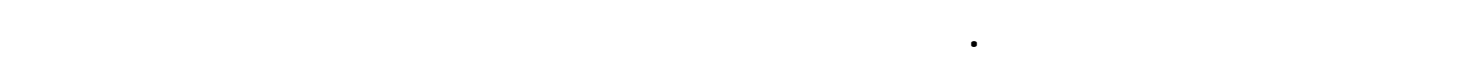

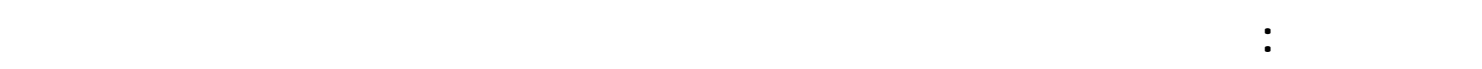

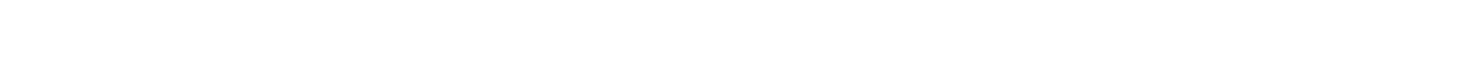

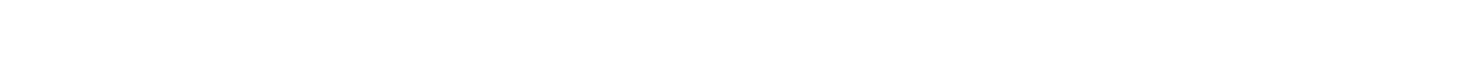

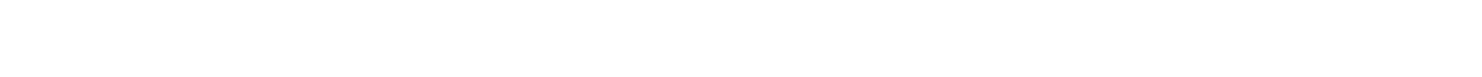

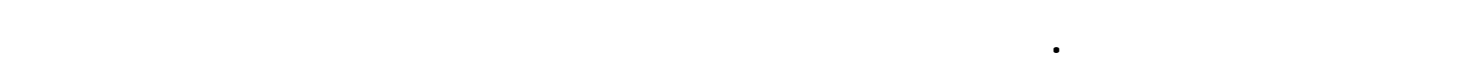
التربية عل المهارات الحيلنية في جنوب فُ لُبقيا.

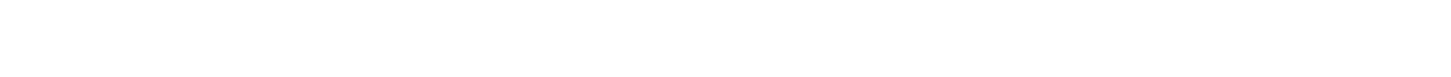

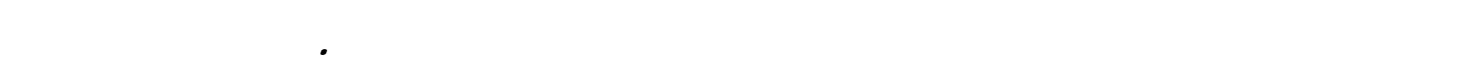

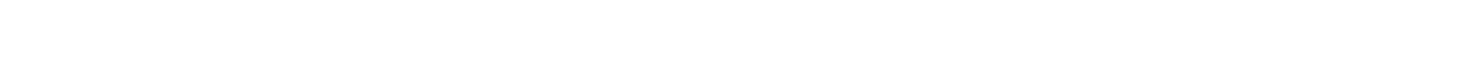

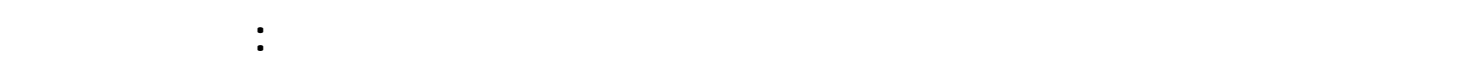

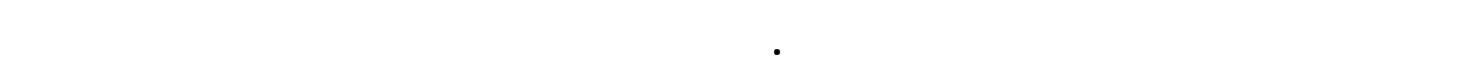

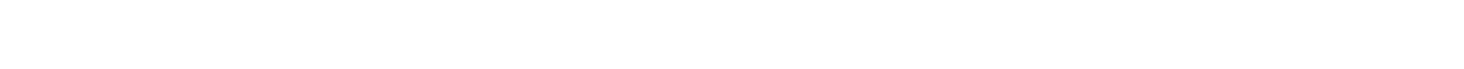

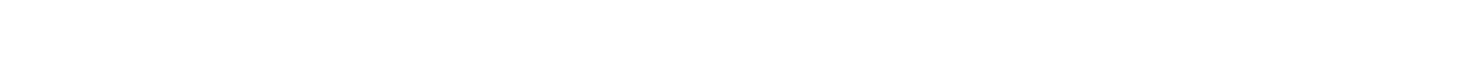
المناعة البشربة المكنسب.

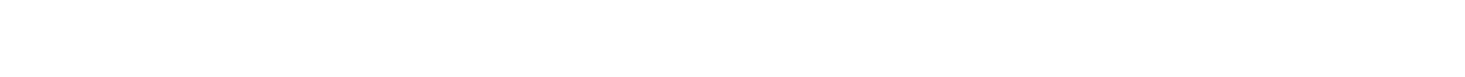

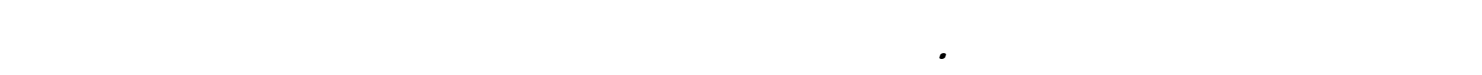

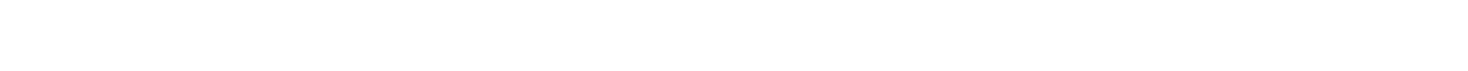




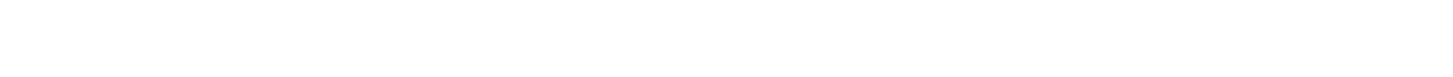 المهارت الحيلتية لن يسم الل دعم وتممق هذا الغنير.}

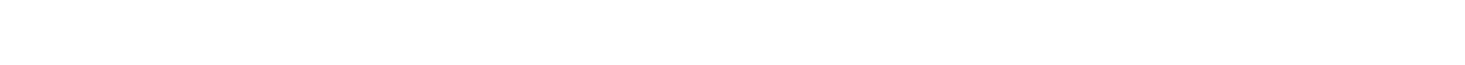

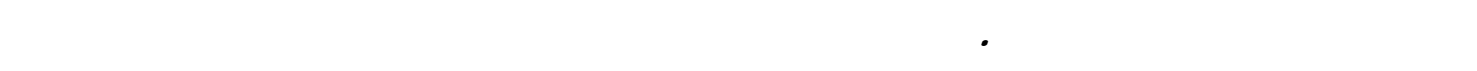

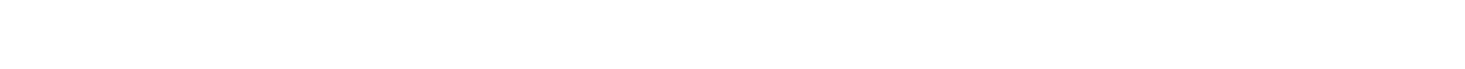

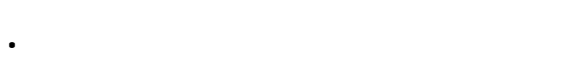

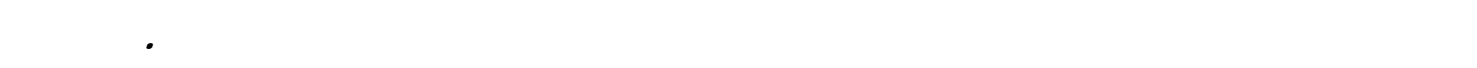

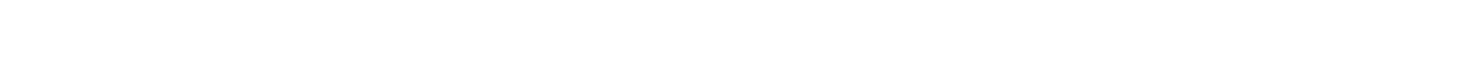

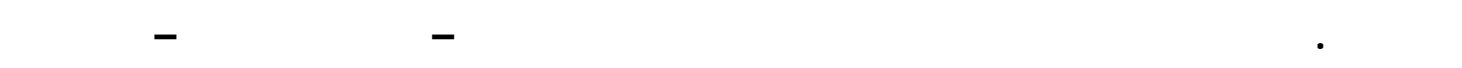
والمهارت المنالسبة للى فمجوعة من هنه المجموعلت المختلفة.

\section{يوليو 2003}

Transitions to Adulthood study team members are Julian May and Ntsiki Manzini, University of Natal, Durban ; Carol Kaufman (now with University of Colorado Health Sciences Center), Naomi Rutenberg, and Kelly Hallman, Population Council ; Lisanne Brown, Ali Mehyrar Karim, Bob Magnani, Kate Mactintyre, and Paul Hutchinson, Tulane University; Stavrou Stavros, Anthea Dallimore, and Ruanne Fensham, DRA Development. Analysis was performed by Robert Magnani, Ali Mehyrar Karim, Kate Macintyre, Lisanne Brown and Paul Hutchinson. 